\title{
ARTigo
}

\section{Migraciones trans: travestis brasileñas migrantes trabajadoras del sexo en Europa*}

\author{
Julieta Vartabedian **
}

\section{Resumen}

En el presente artículo me propongo reflexionar acerca de los procesos transmigratorios que intervienen en la construcción de las identidades de género travestis. Me centraré en las experiencias migratorias de las travestis brasileñas que han viajado y viajan a Europa para insertarse en el mercado del sexo local. Emplearé el concepto "migración trans" para hacer referencia a la especificidad de sus proyectos migratorios: no sólo migran buscando un mayor bienestar social, simbólico y económico, sino que también sus movilizaciones geográficas inciden en la manera de transformar y embellecer sus cuerpos. Las identidades travestis son creadas en estos tránsitos continuos. Al mismo tiempo, se analizará que sus identidades son reconfiguradas en el contexto europeo pues resaltan particularmente su brasileñidad como una estrategia para sobresalir y distinguirse del resto en un mercado del sexo cada vez más limitado por las políticas públicas y la crisis económica.

Palabras-clave: Travestis, Migración Trans, Trabajo Sexual, Europa/España, "Brasileñidad".

\footnotetext{
* Recebido para publicação em 12 de dezembro de 2012, aceito em 15 de abril de 2013.

** Doctora en antropología social y cultural por la Universidad de Barcelona. jlvartabedian@gmail.com
} 


\title{
Trans Migrations:
}

Brazilian Travesti Migrant Sex Workers in Europe

\begin{abstract}
In this paper I will reflect on transmigratory processes involved in the construction of gender identities in travestis. I will focus on the migratory experiences of Brazilian travesties who have traveled to and who are still re-locating in Europe, seeking insertion into the local sex market. I employ the concept "trans migration" to refer to the specificity of their migratory projects: they not only migrate seeking greater social, symbolic and economic well-being, but also their geographical mobility affects how they transform and beautify their bodies. Identities in travesties are created in this continuous process of transiting. At the same time, an analysis will be made of the reconfiguration of their identities in the European context, because their "Brazilian-ness" is highlighted intentionally as a strategy to excel andto stand out from the rest in a sex market increasingly limited by public policies and economic recession.
\end{abstract}

Key Words: Travestis, Trans Migration, Sexual Work, Europe/Spain, "Brazilian-ness". 


\section{Introducción}

El análisis de las migraciones trans ${ }^{1}$ ha estado prácticamente ausente en los estudios en ciencias sociales que analizan la confluencia de las migraciones y el trabajo sexual. El presente artículo pretende reflexionar acerca de la construcción de las identidades travestis ${ }^{2}$ siguiendo como eje analítico sus migraciones transnacionales. Desde la década de los setenta, de forma continua llegan a Europa travestis procedentes dedistintos países de Latinoamérica. No obstante, aunque existan algunas investigaciones brasileñas destacables (Patrício, 2008; Pelúcio, 2008, 2009a; Teixeira, 2008, 2011; Goulart, 2011; Vale, 2005), poco se sabe acerca de las migraciones de las travestis para insertarse en el mercado del sexo europeo.

$\mathrm{Me}$ centraré particularmente en las experiencias transmigratorias de las travestis brasileñas. Como parte del desarrollo de mi tesis doctoral, describiré los constantes tránsitos, corporales y geográfico-espaciales, que las travestis accionan para construir su lugar en el mundo. Mi pesquisa ${ }^{3}$ se originó en Río de

\footnotetext{
1 Utilizo la expresión "trans" como una categoría paraguas que incluye a diferentes identidades: travestis, transexuales o transgéneros, entre otras denominaciones. Sin embargo, me resulta problemático emplearla ya que no pretendo que el carácter reivindicativo y político que se le ha dado al concepto en el contexto español "colonice" las diversas identidades que se mencionan aquí. De todos modos, es una categoría útil porque simplifica la denominación de personas de contextos culturales diversos que no pueden ser llamadas, por ejemplo, 'travestis'. En consecuencia, lo "trans" será utilizado para resaltar únicamente el carácter inclusivo del término.

2 Empleo la categoría emic "travesti" para referirme a un tipo de identidad de género que, generalmente, combina el deseo de in-corporar características físicas y comportamentales entendidas como femeninas con el mantenimiento de una genitalidad masculina de la que no desean desprenderse. Por lo tanto, la categoría 'travesti' que es frecuentemente utilizada en Latinoamérica designa a personas que quieren ser como mujeres sin renunciar a la capacidad de brindar placer sexual a través de sus penes (Benedetti, 2005).

${ }^{3}$ El trabajo de campo duró aproximadamente un año y fue dividido en dos partes. En la primera, permanecí seis meses consecutivos en Río de Janeiro en el año 2008, gracias a la invitación del Programa en Género, Sexualidad y Salud,
} 
Janeiro donde descubrí que un número elevado de travestis provenía de pequeñas ciudades y pueblos pertenecientes a otras regiones del país. Era en Río donde comenzaban a aprender a cómo transformase en travestis y a sobrevivir a través del trabajo sexual, su principal actividad laboral. Más tarde observé que, para subir el siguiente escalón, tenían que cruzar el Atlántico. Después de una etapa de perfeccionamiento, muchas estaban listas para viajar al destino soñado y admirado por todas: Europa. Estos permanentes tránsitos espaciales, de la "gran escuela" carioca a Europa, permitían construir sus identidades como travestis y, más específicamente, modificar sus cuerpos para ser como "bellas" mujeres. En tanto proceso ritual, las travestis emprendían un viaje que era simultáneamente corporal y espacial porque a la vez que transitaban por distintos territorios, iban transformando $y$ embelleciendo sus cuerpos. Por lo tanto, para transformarse en travestis, tenían que transitar ordenadamente por unos itinerarios corporales y, al mismo tiempo, geográfico/espaciales claramente delineados en su universo.

En este trabajo me centraré exclusivamente en las experiencias migratorias de las travestis brasileñas que viajan $\mathrm{o}$ han viajado a Europa. Para ello, comenzaré presentando algunas nociones teóricas básicas sobre la relación entre el trabajo sexual y las migraciones transnacionales. Luego, introduciré el concepto "migración trans" para poder situar las principales ideas del estudio. Asimismo, describiré la importancia que Europa ha tenido, y tiene, para las travestis brasileñas. Me detendré tanto en los relatos de las primeras generaciones de travestis que llegaron a París en los años setenta como en la capacidad que las nuevas generaciones tienen para accionar su brasileñidad al reconfigurar sus identidades y adaptarse a las condiciones actuales del mercado del sexo español. Particularmente, describiré las principales

Instituto de Medicina Social, Universidade do Estado do Rio de Janeiro. La segunda parte se llevó a cabo de forma discontinua en la ciudad de Barcelona entre el año 2009 y el 2011. En ambas ciudades realicé observación participante y entrevistas a profundidad semi-dirigidas a travestis brasileñas, cirujanos/as plásticos/as y agentes de ONG's vinculadas con travestis trabajadoras del sexo. 
estrategias que las travestis emplean en Barcelona para prosperar en un contexto local marcado por la denominada "crisis económica" y por políticas públicas cada vez más restrictivas.

\section{Migraciones y trabajo sexual}

Es cierta la observación que hace Adriana Piscitelli (2009) sobre la difícil conexión entre industria del sexo y migración en los estudios académicos contemporáneos. Asombra esta desconexión cuando se piensa que estas personas "desempeñan un papel importante en la creación de un espacio social transnacional" (Piscitelli, 2009:102). Uno de los principales orígenes de esta omisión se encuentra en los discursos de feministas abolicionistas, que se han posicionado con fuerza en los debates públicos y consideran a las personas que se prostituyen como "víctimas" de la trata de personas. Precisamente el Estado español se rige bajo el sistema abolicionista, es decir, el estado no persigue, no prohíbe ni favorece la prostitución cuando es voluntaria. Sí, en cambio, se actúa en casos de proxenetismo, es decir, cuando existe explotación económica de por medio ${ }^{4}$. El discurso abolicionista basado en la trata de personas (sobre todo, mujeres $)^{5}$, sólo entiende a la prostitución en términos de "explotación", "engaño" y "esclavitud sexual" de las mujeres. En

4 El Código Penal español en la última modificación del 2010 incorpora el delito específico de "trata de personas", entre una de las finalidades de la explotación sexual. Sin embargo, el delito de "proxenetismo" en relación a la prostitución sigue manteniéndose (art. 188.1 del Código Penal). Asimismo, la amplitud en la interpretación de este último delito penal produce incertidumbre, pues determinar quién puede lucrarse al "explotar" el ejercicio de esta actividad podría conducir a situaciones absurdas como castigar a los/as hijos/as de quienes se prostituyen.

5 Como apunta Doezema (2004), este discurso está íntimamente vinculado con el mito y el discurso de "la trata de blancas" del pasado: "en ambos se pone especial énfasis en la juventud de la víctima, en su inocencia y también en el origen 'extranjero' del traficante. [...] [Pero bajo estos discursos] está una vez más el miedo a la independencia de las mujeres y a su sexualidad" (Doezema, 2004:157). 
consecuencia, se comprende que esta confusión entre trata y migración voluntaria de las personas se vuelve irreconciliable.

Existe otra perspectiva de análisis que considera a la trabajadora sexual como una agente con voluntad y capacidad de dirigir su propio destino, una sujeta con voz propia y autonomía. Se reconoce a la prostitución como un trabajo y se lucha por conseguir su legalidad. Al mismo tiempo que se denuncia el estigma de "puta" vivido por todas las mujeres, se contempla el derecho que todas las mujeres tienen a disponer de sus cuerpos y sexualidad. En efecto, se observa cómo se construye una alianza entre las trabajadoras sexuales y el resto de las mujeres. Este enfoque, pues, resalta la autonomía, libertad y agencia de las personas que eligen esta opción laboral por considerarla más beneficiosa que otros trabajos mal pagados y precarios (Pheterson, 1989, 2000; Osborne, 1991, 2004; Juliano, 2002; Agustín, 2004; Garaizabal y Briz, 2007; Holgado, 2008; entre otras).

La industria del sexo es un negocio altamente rentable y por ese motivo este trabajo forma parte del proyecto migratorio de un número importante de personas. Se dice que en muchos países de Europa occidental las mujeres migrantes llegan a constituir aproximadamente el $70 \%$ de las/os trabajadoras/es del sexo (Brussa, 2004). Sin embargo, no sólo migran mujeres para incorporarse en la industria del sexo. Hombres y trans también lo hacen. No obstante, su ausencia e invisibilidad en los debates sobre prostitución son muy frecuentes. De hecho, llama la atención quienes en sus estudios los/as nombran para descentrar momentáneamente la asociación entre trabajo sexual y mujer. En el caso particular de las trans, ellas están excluidas porque el concepto de mujer del discurso dominante se basa en la biología $y$, en consecuencia, según enfoques abolicionistas, son las mujeres (biológicas) a quienes hay que "salvar" y "rescatar" de las redes que tratan con personas (Agustín, 2009). Las personas trans, en tanto "hombres" para la visión oficial, son ignoradas porque numéricamente son poco significativas y "no están en peligro". Asimismo, la activista transexual española y trabajadora del sexo Beatriz Espejo comenta que las transexuales: 
no conciben el hecho de prostituirse como una agresión directa o esclavitud. Por tanto, es más fácil, para una transexual, adaptarse a la prostitución en tanto le sea rentable y rara vez presentará sentimiento de culpa, vergüenza o lesión alguna. [...] La población transexual femenina no es víctima, por ahora, del proxenetismo, el tráfico y la extorsión, quizás también por eso no encuentra razonables las extrapolaciones feministas cuando presentan a la mujer prostituta como víctima de explotación por sistema (2008:133-4).

Las trabajadoras sexuales trans, migrantes, son reconocidas, sobre todo, por las ONG's que trabajan con trabajadoras/es del sexo y desarrollan programas para promover su salud sexual y autonomía. Mediante la entrega de material preventivo y educativo, charlas grupales e individuales, apoyo psicológico, legal y sanitario; estas ONG's promueven el fortalecimiento y la educación socio-sanitaria de las/os "usuarias/os" para minimizar sus prácticas de riesgo. En España, debido a su alto índice de movilidad y a que la gran mayoría son de nacionalidad extranjera y se encuentra en una situación administrativa irregular, es muy difícil cuantificarlas.

Mi experiencia de campo ha demostrado que la vinculación entre travestis y trabajo sexual es muy íntima. No sólo porque esta actividad es necesaria para construir las travestilidades ${ }^{6}$, sino también porque prácticamente no existen otras opciones laborales para ellas. Para la gran mayoría de las travestis trabajadoras del sexo, la prostitución no es una actividad que las avergüence, ni la vivencian con resignación. Por el contrario, es una profesión que las empodera, como diferentes estudios también lo han destacado (Kulick, 1998; Benedetti, 2005; Vogel, 2009; Pelúcio, 2009a). Todas las travestis que llegan a Europa para trabajar en la industria del sexo ya se dedicaban a lo mismo en Brasil. Pensar en Europa hubiera

${ }^{6}$ Incorporo el término travestilidad utilizado en los últimos años en Brasil (Peres, 2005; Vale, 2005; Patrício, 2008; Duque, 2009; Pelúcio, 2009a; entre otros/as) para hacer referencia a la heterogeneidad de las identidades de las travestis. 
sido imposible sin estas experiencias laborales previas. Asimismo, todo el proceso de transformación travesti no está organizado al azar, sino que sigue una serie de pasos que determinarán cuando ya se está lista para el viaje transnacional. El trabajo sexual es, pues, un elemento fundamental del proceso identitario $y$ migratorio de las travestis.

\section{Migraciones trans}

Las llamadas migraciones por motivos económicos, fueron hegemónicas en las investigaciones sobre migración en ciencias sociales. En los últimos años, un número cada vez más creciente de investigadores/as incorporan la articulación de categorías como el género, los afectos y la sexualidad para entender los tránsitos transnacionales (Piscitelli et al., 2011). Al indagar algunas referencias teóricas para estudiar los procesos de movilización de las travestis, me aproximé en primer lugar a las categorías migración sexual (Cantú, 2002; Parker, 2002; Pichardo, 2003; Vale, 2009) y migración queer (Fortier, 2003; Gorman-Murray, 2007; Luibhéid, 2008) como posibles herramientas de análisis. Ambas categorías describen los deseos y las prácticas sexuales de personas que abandonan su lugar de origen y buscan un nuevo sitio donde vivir su sexualidad de forma diferente. La totalidad de estos estudios hacen referencia a las experiencias migratorias de gays y lesbianas.

Las motivaciones que llevan a gays y lesbianas a migrar son diversas. Por ejemplo, Pichardo (2003) sistematiza las principales causas migratorias de un grupo de gays y lesbianas de nacionalidad extranjera entrevistados/as en España: escapar del control social (la familia), empezar de cero y establecer una nueva identidad; buscar el anonimato de una gran ciudad; encontrar un ambiente de mayor respeto; mayores oportunidades de sociabilidad; conseguir mejores tratamientos contra el $\mathrm{VIH}$; conseguir residencia en países que permiten formalizar las relaciones homosexuales; $y$, huir de países con condenas penales que pueden llegar hasta la muerte. Estas referencias, aunque pertinentes al pensar en las migraciones de travestis, transexuales 
y transgéneros, son limitadas para captar sus experiencias de movilización. En el caso de las travestis brasileñas, también buscan ganar dinero (generalmente, mediante el trabajo sexual) y modificar sus cuerpos para ser más "femeninas y bellas". La capacidad que tienen de hacerse a sí mismas, a través de sus intervenciones corporales, es un factor de vital importancia para entender sus tránsitos. En consecuencia, las investigaciones que se ubican bajo el concepto de migraciones sexuales o queer, si bien han sido y son útiles, pues al incorporar la variable 'sexualidad' en los análisis migratorios descentran la hegemonía económica como principal perspectiva de estudio, no contemplan la particularidad de las migraciones trans.

Propongo el uso del concepto "migración trans" para hacer referencia a los procesos migratorios que reflejan la particularidad de las experiencias de travestis, transexuales o transgéneros. Las personas trans migran para encontrar mayor libertad y respeto para expresar y vivir sus identidades de género y sexualidad, pero también buscan - simultáneamente - un escenario económico beneficioso para desarrollar una actividad laboral. En el caso de las travestis brasileñas, el trabajo sexual es una fuente de ingresos muy importante tanto por las ganancias económicas que conlleva, como por ser un elemento fundamental del proceso de construcción de las travestilidades. Al hablar de migración trans se resalta tanto la capacidad de agencia y las características vinculadas a la sexualidad y al género, como los procesos económicos en el que están insertas las personas que migran (Howe et al., 2008). En consecuencia, no se pueden aislar las migraciones trans de los condicionamientos sociales, políticos y económicos que movilizan dichas migraciones. Sobre todo, la particularidad de las migraciones trans reside en que no sólo están cruzando unas fronteras espaciales (nacionales o transnacionales) sino que, al mismo tiempo, construyen su propia identidad pues, como lo hacen las travestis, mientras van migrando van modificando y feminizando más sus cuerpos. Por lo tanto, cuando se habla delas migraciones de las travestis no sólo me refiero a sus desplazamientos espaciales, sino que describo también sus tránsitos 
por los límites de un territorio corporal (King, 2003; Howe et al., 2008; Vogel, 2009; García y Oñate, 2010). Para transformarse en travesti es necesario someterse a una serie de procedimientos cosméticos, estéticos y/o médicos para performar un determinado tipo de ideal femenino. Asimismo, la gran mayoría de estas modificaciones sólo pueden llevarse a cabo si se ha migrado a entornos sociales y laborables que estimulan ese transformarse en travesti.

A continuación se analizará cómo Europa no es simplemente una escala más entre los numerosos territorios que las travestis brasileñas pueden transitar para transformar sus cuerpos o para profesionalizarse como trabajadoras del sexo. Sus migraciones transnacionales a Europa, ya desde los años setenta, constituyen un evento de decisiva influencia en el desarrollo de las travestilidades. Europa no sólo ha propiciado que las primeras generaciones de travestis comiencen a embellecerse definitivamente como mujeres, sino que también ha permitido que un número importante de travestis ganen mucho dinero $y$ que, aunque algunos condicionamientos sociales, políticos y económicos hacen que las ganancias mermen en la actualidad, el viaje a Europa siga considerándose como una actividad que da prestigio y empodera a quienes con "éxito" han podido dar un paso más - quizás el últimoen esta carrera para transformarse en travestis.

\section{Las pioneras}

A finales de los años sesenta, Daloá ${ }^{7}$ fue la primera brasileña en llegar a París y trabajar como bailarina en las exclusivas casas de cabaret Madame Arthur y Carrousel de Paris ${ }^{8}$, pertenecientes al mismo dueño Monsieur Marcel. Luego, en el año setenta surgieron nombres como el de la famosa Regina y Vanessa. En realidad, en

\footnotetext{
7 Todos los nombres de las participantes de la investigación son ficticios, con la excepción de las personas que están muertas (como Daloá).

8 El Carrousel de Paris llegó a convertirse en un cabaret con un nivel más alto y refinado que su antecesora Madame Arthur. En el Carrousel trabajaron las famosas artistas transexuales Coccinelle y Bambi, entre otras célebres transexuales europeas.
} 
aquella época no se puede aún pensar que los cuerpos de Daloá y de sus sucesoras se asemejaban a las travestis contemporáneas. De hecho, ellas llegaron a París desde Brasil como actores transformistas. En Brasil, no sólo las técnicas de transformación corporal no estaban aún desarrolladas, sino que tenían prohibido exhibirse como mujeres las 24 horas del día. Solamente eran tolerados los transformismos/transvestimientos en los teatros $y$ durante el carnaval. Aún durante los años setenta, quienes se animaban a salir a las calles con una apariencia femenina eran duramente reprimidas o, en el peor de los casos, directamente exterminadas durante la dictadura brasileña (Figari, 2009).

Los espectáculos de transformistas y transexuales estaban en pleno auge en las principales ciudades europeas. En estos escenarios las artistas cantaban en vivo, bailaban y desplegaban sus "encantos femeninos" frente a un selecto público maravillado ante la posibilidad de que esas "bellezas" sean/hayan sido hombres. Cuando le pregunté a Regina en Río de Janeiro si las mujeres también trabajaron en el Carrousel, me contestó de forma categórica: "No, mujeres nunca entraron, mujeres jamás. U operadas [transexuales] o travestis. Sólo tenía que tener pecho". 9 Para comenzar a tener pecho y a feminizar sus cuerpos, brasileñas como Regina y Vanessa conocieron por primera vezlas hormonas en Europa.

En Barcelona esta modalidad de show también fue muy famosa. Sobresalieron los locales como Barcelona de Noche o Gambrinus. Según las memorias de Pierrot, actor y showman de los principales espectáculos en Barcelona, "[e]n los años setenta el éxito de las trans en el espectáculo era tan espectacular que ninguna sala perdía la oportunidad de tener en su elenco 'el desafío a la imaginación más desbordada" (Pierrot, 2006:155). Una de las primeras brasileñas que llegó a España fue Lorena Capelli, quien murió por las complicaciones que surgieron cuando le realizaban una vaginoplastia. Cuentan que fue una de las pocas

9 "Não, mulheres nunca entraram, mulheres jamais. Ou operadas [transexuales] ou travestis. Só tinha que ter peito". 
que llegó a Europa ya vestida de mujer, pues su padre formaba parte del cuerpo diplomático y obtuvo un documento oficial en el que se le autorizaba a ir por las calles de Brasil con aspecto "femenino". De todos modos, comparada con París, la ciudad de Barcelona no fue el principal destino para las travestis brasileñas. Paulatinamente llegaron aquí una vez que la "época dorada" de París comenzó a decaer ya en los años ochenta.

Todas mis entrevistadas travestis con más edad, reconocieron que el éxito que estas pioneras tuvieron, particularmente en París, fue sorprendente. En estos shows fueron admiradas y respetadas, como nunca, por los hombres europeos. Al mismo tiempo, se hicieron más "bellas" a través del empleo de diversas prácticas estéticas como el "bombeo" de silicona líquida en sus cuerpos, y cuando volvieron a Brasil generaron un gran impacto mediático entre el resto de sus colegas. Como Regina asegura al ser entrevistada en Río, "ellas comenzaron a ir para allá pero sólo que no podían ser estrellas del Carrousel" "10. Muy pocas travestis consiguieron entrar como artistas en estas casas. No obstante, rápidamente descubrieron que sus incursiones como trabajadoras del sexo en las calles de París les daban mucho dinero.

A partir de mediados de los años setenta un número importante de brasileñas comenzó a viajar a París para dedicarse exclusivamente al trabajo del sexo. Trevisan (2007 [1986]) asegura que se llegaron a organizar vuelos chárter para transportar especialmente a las travestis a París: los llamados "vuelos de la belleza" (Oliveira, 1994; Vale, 2005). Aunque es muy difícil llegar a cuantificarlas, Trevisan (2007 [1986]) considera que de las 700 travestis que entonces trabajaban en Francia, 500 eran brasileñas. Este dato no ha sido justificado por el autor ni ha mencionado las fuentes. Por consiguiente, si bien la información no es del todo fiable, sólo es mencionada para dar cuenta del impacto que estas migraciones han tenido en los estudios de algunos/as investigadores/as. En el excelente trabajo de Green (2000:346)

10 "[...] elas começaram a aparecer quando começaram a saber do meu sucesso no Carrousel". 
también se lee que "centenares o tal vez millares" de travestis tuvieron la oportunidad de obtener grandes ganancias financieras en el exterior. El autor asegura que a finales de los años setenta Brasil comenzó a "exportar" travestis para Europa. Asimismo, la investigación de Vale (2005:170) sobre travestis brasileñas en Francia manifiesta que, fruto del poder y el dominio que tenían en el campo de la prostitución, en la década de los ochenta la palabra brésilien se convirtió en sinónimo de travesti.

$\mathrm{El}$ auge de esta "época dorada" en París llegó, pues, entre los años '78 y '80, año en que fue asesinada Elisa. Elisa fue una travesti brasileña muy influyente y poderosa en París. Encargada de controlar tanto el negocio de la prostitución como de la distribución y aplicación de la silicona líquida. Los "bombeos" de silicona hechos por brasileñas comenzaron en París y Elisa fue la gran precursora. El asesinato, en manos de Claudia, de la "reina de Pigalle" marcó el inicio del declive de los años más fructíferos de las travestis brasileñas en Europa. Aunque muchas quisieron ocupar el lugar de Elisa, no lo consiguieron. Comienza un período que algunas entrevistadas consideran como "marginal" pues, ya sin el control efectivo de Elisa, afloraron muchas rivalidades, envidias, amenazas y "escándalos" 11 entre las propias travestis. Al mismo tiempo, crecieron las presiones por parte de las autoridades francesas: entre los años '80 y '84 las expulsiones se multiplicaron por irregularidades en sus visados. En fin, el ambiente en torno a las travestis brasileñas se volvió cada vez más pesado y opresivo en Francia y a partir de la segunda mitad de los años ochenta otros destinos fueron elegidos en Europa. Durante los años noventa y relativamente hasta la actualidad, Italia se convirtió en la gran meta de las nuevas generaciones de travestis. Países como España, Alemania, Suiza y Holanda son incorporados a partir del año 2000

\footnotetext{
${ }^{11}$ Kulick y Klein (2003) analizan el uso que las travestis brasileñas hacen del "escándalo". Observan que es una forma de acción política que tiene por finalidad causar vergüenza, es decir, ellas se reconocen como seres abyectos y amenazantes que, en determinados contextos, accionan dicho poder para causar vergüenza en generalmente- los clientes, para lograr así sus objetivos (ganar dinero).
} 
(Teixeira, 2008). Puntualmente, las migraciones a España se intensificaron a partir de la segunda mitad de la década del 2000.

\section{La importancia de Europa}

El "descubrimiento" de Francia y, posteriormente, del resto de países europeos para trabajar en el mercado del sexo forma parte de un intento de las travestis por encontrar una vida mejor. Esto no se traduce únicamente en la posibilidad de ganar dinero y bienes materiales, sino también en hallar un ambiente donde sean respetadas, lejos de la violencia experimentada en Brasil al encarnar sus identidades de género. Aunque las rutas migratorias sean reconfiguradas permanentemente y las condiciones políticas y económicas de los países de destino hayan cambiado, sus motivaciones para llegar a Europa siguen siendo prácticamente las mismas a lo largo de los años.

En los últimos años, algunas investigaciones brasileñas se han centrado en estudiar y acompañar las migraciones de travestis a Europa, específicamente, a España (Patrício, 2008; Pelúcio, 2008, 2009b, 2011), Italia (Teixeira, 2008, 2011; Goulart, 2011) y Francia (Vale, 2005). También trabajos más antiguos en torno a las travestis brasileñas han detectado la importancia de sus tránsitos a Europa (Silva, 1993; Oliveira, 1994; Kulick, 1998). Estos estudios coinciden en que Europa representa un ascenso social en el universo de las travestis. Sus conquistas económicas (sobre todo, quienes pueden comprar sus casas en Brasil) son exhibidas como verdaderos trofeos que permiten reconocer a las travestis "exitosas" que se diferencian de las demás. Al mismo tiempo, los cuidados corporales, las nuevas cirugías estéticas realizadas, las ropas de marcas importadas, los perfumes caros y las joyas, dan cuenta del prestigio y del "glamour" alcanzados a través de sus estancias en Europa (Teixeira, 2008; Pelúcio, 2009a). Se valora asimismo la posibilidad de acceder a otras culturas, dominar otras lenguas, adquirir nuevas experiencias, sentirse respetadas y deseadas por "hombres de verdad" que podrían llegar a convertirse en sus 
maridos $^{12}$. El relato de Francisca, quien reside en Barcelona, revela el principal motivo por el cual no desea volver a vivir en Brasil:

Muchas se apegan a Europa y dejan Brasil... ¿Por qué? No porque aquí está el dinero, las personas piensan que es por causa del dinero, ino! Es por los malos tratos. Nosotras no tenemos derecho de entrar en un restaurante y ser vistas como ser humano. Nosotras en Brasil somos vistas por el coche, por la marca de la ropa que estás usando, no somos vistas como ser humano. [...] Aquí en Europa la travesti es tratada como un ser humano normal. Aquí los hombres dan más valor a la travesti. Hay hombre que hasta larga a su mujer para quedarse con una travesti ${ }^{13}$.

La búsqueda de la "normalidad", deseada por Francisca, se convierte, pues, en una importante razón para quedarse en Europa. Todas las entrevistadas durante mi trabajo de campo, tanto quienes aún viven o han vivido en Europa, coinciden en resaltar que, como en ningún otro sitio, en Europa se sienten/se han sentido libres y respetadas. Sin embargo, como las experiencias son diversas, no todas aceptan abandonar definitivamente Brasil $e$, incluso, consideran una "traición al país de origen" el hecho de querer residir en Europa (Goulart, 2011:312). A muchas sólo les interesa pasar unos años en Europa para ganar el suficiente dinero buscando conseguir una buena vida para ellas mismas $y$, muchas veces, para ser el sostén

\footnotetext{
12 Término emic que permite nombrar a los compañeros de las travestis, independientemente del tiempo de duración de la relación o de la existencia de algún vínculo formal.

13 "Muitas se apegam à Europa e deixam o Brasil... Por que? Não porque aqui está o dinheiro, as pessoas pensam que é por causa do dinheiro, não! É pelos maus tratos. Nós não temos direito de entrar num restaurante e ser vistas como ser humano. Nós no Brasil somos vistas pelo carro, pela marca da roupa que você está usando, a gente não é vista como ser humano. [...] Aqui na Europa a travesti é tratada como um ser humano normal. Aqui os homens dão mais valor à travesti. Tem homem que larga até amulher para ficar com travesti”.
} 
económico de sus familias en Brasil ${ }^{14}$. El dinero empodera a las travestis frente a su familia y les permite reconstituir las relaciones dañadas en el pasado así como acentuar las fisuras.

En definitiva, Europa representa una importante promoción a nivel material, simbólico y corporal. Las "europeas" ${ }^{15}$ son reconocidas por su "belleza", "refinamiento" y "sofisticación", o sea, como personas "viajadas" que llegaron a Europa y encarnaron una serie de ideales, a tal grado, que cuando vuelven a Brasil - de forma transitoria o permanente- son positivamente valoradas. Sin embargo, no todas las "europeas" están de acuerdo en que la vida de ellas es mucho mejor que la del resto por el sólo hecho de vivir en Europa. Como Márcia reconoce desde Barcelona: "En Brasil todos piensan que aquí comemos caviar" 16. Por el contrario, la vida en Europa puede ser muy dura. La denominada "crisis económica" que se inició en los últimos años, las políticas municipales que restringen y prohíben el trabajo sexual callejero, la soledad o el miedo a las deportaciones, son algunas dificultades que atraviesan y que delinean un panorama complejo en donde cada vez es más difícil convertirse en una travesti "exitosa".

\section{El encanto de la brasileñidad ${ }^{17}$}

Finalmente, se reflexionará acerca de cómo las identidades de las travestis brasileñas son reconfiguradas en el contexto

\footnotetext{
${ }^{14}$ Piscitelli (2009) distingue que las mujeres brasileñas que trabajan en la industria del sexo en Europa (España e Italia) también suelen regresar una o dos veces al año a Brasil, dependiendo del estatuto migratorio y de las condiciones económicas de cada una. En estos viajes se afianzan los lazos afectivos con sus familias y gestionan las inversiones que han sido facilitadas con el dinero ganado en Europa para, en muchos casos, planear su retorno definitivo al país.

${ }^{15}$ Término emic que se utiliza para referirse a las travestis que han vivido o viven en Europa.

16 "No Brasil todos pensam que aqui a gente come caviar".

${ }^{17}$ Concepto propuesto por Piscitelli (2011:5) y que alude a los trazos "étnicos" asociados al Brasil.
} 
europeo. Específicamente me centraré en la inserción de las travestis en el mercado del sexo español. Como Patrício (2008) manifiesta: si en Brasil, las que circulan por el mundo, se destacan como "europeas", ya en Europa ellas se distinguen como brasileñas. Los escenarios, las prácticas sexuales y las imágenes creadas en torno a las travestis son diferentes en los mercados del sexo español y brasileño. Se observa que cuando los contextos son modificados, se alteran asimismo las marcas identitarias (Piscitelli, 2011). Se examinará la producción de imágenes corporales en torno a las mujeres brasileñas, en general, y a las travestis, en particular, para entender cómo se acciona la brasileñidad una vez que se han cruzado las fronteras nacionales.

Piscitelli (2007, 2011:10) puntualiza que, en Brasil, los debates en torno a la integración de las mujeres brasileñas en el mercado transnacional del sexo se han llevado a cabo a partir de una cierta construcción de la feminidad nacional, altamente sexualizada y definida por el "color" (Moutinho, 2004). Las imágenes de mulatas y negras producidas históricamente a partir del Brasil colonial explican, según este discurso, la notoriedad que las brasileñas tienen en la industria del sexo transnacional como bienes de consumo "exóticos" 18 . Esta sexualización de la "raza" ha permitido que Brasil creara y exportara uno de sus principales símbolos nacionales: el de sus mulatas y negras irresistibles, que contornean sus caderas al ritmo del samba (Edmonds, 2002; Corrêa, 1996). De acuerdo a Piscitelli, "la imagen de la mulata construida como objeto de deseo y símbolo nacional aparece como síntesis de la percepción sexualizada de la brasileñidad" (2011: 11). Estas representaciones altamente sexualizadas contribuyen a que la

${ }^{18}$ Según Kempadoo (apud Piscitelli, 2007b:27), el exotismo se basa en la admiración, valoración y atracción por el otro. Sin embargo, analizando los procesos de exotización contemporáneos regidos por movimientos económicos y culturales globalizantes, termina siendo una forma de racismo, con la única diferencia de que el exotismo no sitúa la alteridad en un lugar inferior. No coincido con este último punto señalado por la autora pues considero que, aunque con otras fórmulas, el exotismo sí termina posicionando al/a laotro/a en una posición inferior. 
asociación entre ser brasileña y ser prostituta surja de forma casi inmediata en el contexto migratorio (Pontes, 2004; Mayorga, 2011). Sólo las mujeres con mayor escolaridad, que no son consideradas negras y cuentan con una mejor posición social en los países receptores, pueden estar "menos afectadas por esas nociones de brasileñidad" (Piscitelli, 2011:15).

Diversas investigaciones sobre mujeres brasileñas trabajadoras en el mercado del sexo español coinciden en describir que en estos escenarios ellas se identifican como brasileñas y se apropian de algunos atributos como ser "calientes" y "morenas" (Piscitelli, 2011). Es decir, ellas incorporan el discurso dominante patriarcal y colonial para alcanzar determinadas metas a través de sus trabajos como profesionales del sexo: autonomía, independencia económica o libertad (Piscitelli, 2004; Mayorga, 2011). No obstante, Piscitelli destacó que en la industria del sexo española, a través de entrevistas que hizo a clientes y empresarios de locales de alterne, la sexualidad que racializa a las brasileñas como "morenas" no las ubica en una posición privilegiada con respecto al resto, sino que frecuentemente las trabajadoras del sexo de "color" son asociadas con las colombianas y cubanas. Esto significa que, en Cataluña ${ }^{19}$, donde llevó a cabo su investigación, "las brasileñas tienden a diluirse en una categoría regional, como latinoamericanas" (Piscitelli, 2011:19). Paralelamente, a través de los relatos de las propias trabajadoras del sexo, ellas destacan su singularidad como brasileñas a través de cualidades como el cariño, la alegría, la simpatía y el cuidado con los clientes (Piscitelli, 2007, 2011). Sintetizando lo expuesto, la autora argumenta que:

en estos sectores altamente mercantilizados de la industria del sexo en España, los atributos que esas migrantes subrayan para afirmar su brasileñidad son la afectuosidad y el cuidado. En este escenario, la supuesta "superioridad" concedida a esta nacionalidad en virtud de una sexualidad exacerbada, asociada a un saber específico y vinculado a la

${ }^{19}$ Barcelona es la capital de esta comunidad autónoma española. 
valorización del color "moreno" se tornan secundarios. Las cualidades destacadas tienen cierto sabor a domesticidad. Accionándolas, las entrevistadas procuran posicionarse en un contexto marcado por la competencia entre mujeres de diversas nacionalidades (Piscitelli, 2011:22).

Con respecto a las travestis brasileñas que trabajan en el mercado del sexo español, se revelan algunos aspectos significativos en relación a los análisis recién expuestos. Las travestis también activan su identidad como brasileñas en sus migraciones transnacionales, pero en vez de acentuar cualidades relacionadas al temperamento ("alegres" y "cariñosas"), ellas privilegian sus cuerpos como los principales marcadores identitarios de su brasileñidad. Es decir, destacan que son más "calientes" y "sensuales" y, al mismo tiempo, que sus cuerpos son "especiales". Algunos relatos de entrevistadas que viven o han vivido en Europa:

Es raro que haya una travesti, una transexual, con cuerpo bonito en España. ¿Viste ya una travesti española realmente bonita? iY brasileña ya viste a varias! [...] Cuerpo perfecto, marquita del biquini [hecha por el sol], bronceada... Brasil, siempre $^{20}$ (Roberta).

Las travestis brasileñas son bonitas. Ellas buscan la perfección, ellas tienen una cosa que las de afuera no hacen ese tipo de cuerpo ${ }^{21}$ (Lina).

Los cuerpos de las otras no son tan redondeados, no son tan femeninos como los nuestros. Los nuestros son más femeninos, buscamos desarrollar una feminidad,

\footnotetext{
20 "É raro ter uma travesti, uma transexual, com corpo bonito na Espanha. Você já viu travesti espanhola mesmo bonitona? E brasileira você já viu várias! [...] Corpo perfeito, marquinha de biquini, queimada... Brasil, sempre”.

21 "As travestis brasileiras são bonitas. Elas procuram a perfeição, elas têm uma coisa que as de lá fora não têm, esse tipo de corpo".
} 
¿entiendes? Las brasileñas son más fáciles de quedar más redondeadas ${ }^{22}$ (Keyla).

Existe una creencia entre las propias travestis, que son únicas, que la particularidad de sus cuerpos las distingue del resto. Esta convicción puede tener sus fundamentos en el peso que la llegada de las brasileñas tuvo a finales de los setenta en el mercado del sexo europeo y en la difusión que tuvieron en algunas técnicas de embellecimiento como el "bombeo" de silicona líquida. Reyna, otra informante, sostiene que "todas buscan el prototipo brasileño, tanto, que en las aplicaciones de silicona somos las mejores, inclusive en las [cirugías] plásticas también, los cirujanos plásticos [...] tenemos a los mejores en ese campo. Entonces somos copiadas por todo el mundo, somos buscadas" ${ }^{23}$. Las travestis brasileñas, pues, una vez que transitan por las fronteras de su país, se reconocen como "las más bonitas". Sus cuerpos "perfectos" se convierten en el principal distintivo que las diferencia de las demás travestis en el amplio y competitivo mercado del sexo europeo.

Al mismo tiempo, se erigen como grandes amantes, capaces de dar mucho placer y gozo a sus clientes. Para ello aprovechan el elevado grado de erotización creado en torno a su brasileñidad. Generalmente, existe una tendencia a que sexualicen su "color" moreno/mulato. Si se examinan algunas auto-identificaciones que las travestis brasileñas emplean para presentarse en uno de los principales sitios en Internet, donde anuncian sus servicios en apartamentos privados en España ${ }^{24}$, se descubrirán expresiones

\footnotetext{
22 "Os corpos das outras não são tão arredondados, não são tão femininos como os nossos. Os nossos são mais femininos, procuramos desenvolver uma feminilidade, entendeu? As brasileiras são mais fáceis de ficarem mais arredondadas".

23 "[...] todas procuram o protótipo brasileiro tanto que nas aplicações de silicone nós somos as melhores, inclusive nas plásticas também, os cirurgiões plásticos [...] nós temos os melhores nesse campo. Então nós estamos copiadas pelo mundo todo, estamos procuradas".

${ }^{24} \mathrm{Me}$ refiero a www.erosguia.com. En este portal se puede acceder tanto a los servicios de mujeres como de travestis. Una vez que se elige ingresar al espacio
} 
como: "morena de infarto", "mulata cachondísima", "mulata de mucho placer", "morena guapísima de piel canela, caliente como el verano" o "mulata brasileira, tan exuberante y caliente como mi tierra". En algunos anuncios, mencionan cualidades como "piel bronceada", "exótica" o "morena bronceada" para indicar, junto a otras características, cuán "calientes" son. Incluso se encuentra el anuncio de una travesti brasileña, fenotípicamente "bronceada", "morena" o "mulata", que no menciona ninguna de estas expresiones para describirse pero se observa que en todas sus fotografías se la ve con vestido diminuto de leopardo, con largos pendientes de plumas y posando inclusive en cuatro patas delante de abundante vegetación natural. Estas imágenes representan a una travesti portadora de una sensualidad "exótica", "salvaje" e "incontrolable". Difícilmente, una travesti rubia y "blanca" posaría de esta manera para representar un determinado tipo de sexualidad casi animal (hooks, 1997).

La "negritud sexualizada" (Pelúcio, 2008:12) que accionan las travestis es un bien valorado en sus contextos migratorios transnacionales. Por el contrario, en Brasil las travestis valoran como un ideal estético el ser blancas y rubias. Como este ideal es inalcanzable para la mayoría de travestis y mujeres brasileñas que son morenas, muchas emplean algunas prácticas para blanquear su apariencia: alisan y aclaran sus cabellos, utilizan mucha base de maquillaje, exhiben las marcas del bikini hechas cuando toman sol para mostrar cuan blancas son, entre otras prácticas. Por lo tanto, si en Brasil deciden estratégicamente blanquearse, en Europa valorizan la "belleza negra" como un elemento que les otorga prestigio en el mercado del sexo transnacional (Duque, 2009). Sin

exclusivo de las travestis, se puede visualizar en la página principal las fotos de todas las travestis anunciadas, con su nombre y la ciudad donde se encuentran (casi exclusivamente, Barcelona y Madrid). En las fotos posan con lencería muy erótica y semidesnudas, exhibiendo pechos, nalgas y, en muchísimos casos, sus penes erectos. Cliqueando en las fotos o los nombres se accede a la información completa de la travesti seleccionada (edad, idiomas que habla, teléfono, descripción general de cómo es, los servicios que ofrece y las tarifas), también se pueden ver diferentes fotos e, incluso, algunas adjuntan vídeos. Existen asimismo anuncios destacados que presentan fotografías de mayor tamaño que el resto. 
embargo, las brasileñas de "color", en el mercado del sexo español, cuentan con el mismo estatus que las mulatas/negras de Venezuela, Cuba, Panamá, Colombia, (quienes son encontradas también en los portales publicitarios en Internet), Ecuador y Perú (menos publicitadas en Internet, intentan trabajar más en la calle). Aún así, ser mulata/morena/bronceada es un valor a destacar, como, finalmente, se describe en este anuncio: "[soy] un encanto de travesti brasileña recién llegada a la ciudad, la mulatita tan exuberante y ardiente como su país de origen!" 25

Esta "fogosidad" sexual, que ha sido construida de acuerdo a un modelo colonial/"racial", se condensa en la visión sexualizada de la brasileñidad. Con esto quiero decir que, en realidad, más allá del "color", son las brasileñas quienes están siendo sexualizadas y se sexualizan a sí mismas según este modelo. Conviene, pues, considerar más a los marcadores étnicos que "raciales". Es útil el significado que Pontes (2004:234) emplea para hablar de etnicidad en su investigación sobre la representación de las mujeres brasileñas en los medios de comunicación portugueses. Considera la etnicidad como un proceso de identificación construido en el contexto migratorio. Aunque este proceso esté asociado con una ideología del mestizaje que exotiza y sensualiza a las mujeres, "las agentes no precisan ser exactamente mestizas: su brasileñidad ya les confiere esa 'filiación'" 26 (Pontes, 2004:234). Será en la intersección entre etnicidad y nacionalidad donde las travestis que hacen un uso estratégico de su brasileñidad se describirán como:

Hola amores soy Carolina la travesti más guapa que vas a conocer fúe [sic] nombrada miss Brasil por ser la más guapa

\footnotetext{
${ }^{25}$ Disponible en: http://barcelona.tuguiaerotica.com/travestis-escorts/samiradanner/2806/. Acceso 7/5/12.

26 " [...] as agentes não precisam ser exatamente mestiças: sua brasilidade já lhes confere esta 'filiação"'.
} 
y elegante entre todas. Soy puro fuego en la cama ven a probar de mi cuerpo de top model ${ }^{27}$.

Soy una chica brasileña, muy caliente con unas medidas impresionantes y reales como tú jamás has visto. Cien por cien activa, yo no soy dulce, ni dócil, muy cañera, muy dominante $e^{28}$.

Hola soy una brasileira, 23 años, bellísima, 1.90, cuerpo de seda, refinada, muy morbosa caliente y puro fuego en la cama $^{29}$.

Estos anuncios seleccionados en otro portal de Internet para travestis en España ${ }^{30}$ reflejan que el ser "puro fuego en la cama" no está exclusivamente asociado con el hecho de ser

${ }^{27}$ Disponible en: $<$ http://www.taiakashemales.com/modelos/espana/carolina_scarlat.shtml >. Acceso en: 21/4/12.

${ }^{28}$ Disponible en: $<$ http://www.taiakashemales.com/modelos/espana/alexandra_bittencourt.shtml> [acceso 21/4/12].

${ }^{29}$ Disponible en: <http://www.taiakashemales.com/modelos/espana/safira.shtml> [acceso 22/4/12].

${ }^{30}$ Taiakashemales es un portal español para el anuncio exclusivo de travestis. El mismo se organiza agrupando bajo la categoría "Travestis VIP" a los anuncios que son destacados y enumerando las 24 ciudades más importantes en España donde se ofrecen los servicios de todas las travestis en cada ciudad.Los anuncios que aparecen en la primera página de cada ciudad consisten en la foto de una travesti, como en Eros Guía, de cuerpo entero, luciendo lencería erótica y semidesnudas, exhibiendo sus partes corporales más "calientes". Acompaña la foto el nombre de la travesti $y$, en muchos casos, una bandera con su nacionalidad. Una vez que se cliquea la foto de la travesti elegida, se accede a toda una información detallada sobre las características de la travesti (de dónde proviene, medidas, gustos sexuales) y de los servicios que ofrece, junto a su teléfono personal. También se adjuntan una serie de fotografías que pueden ser ampliadas cliqueando sobre ellas. Este portal cuenta con un foro para clientes (intercambian información entre ellos, recomiendan a las mejores travestis, comparten sus experiencias) y para las travestis (hacen anuncios de sus traslados a otras ciudades, contactan y entablan conversaciones con clientes, entre otras actividades). 
mulatas/negras, sino con encarnar lo que significa ser una travesti brasileña. Para ello se debe considerar un elemento imprescindible para definir la relación que ellas establecen con sus clientes: sus penes. Todos los anuncios de travestis hechos a través de Internet o de periódicos describen su "dotación". La descripción es, generalmente, muy detallada ya que mencionan los centímetros (aseguran que "reales") de largo y grosor. También aluden a una serie de adjetivos como "dura", "empalmada", "lechera", "enorme" o "jugosa" que dan cuenta del potencial que tienen entre sus piernas. Se observa, asimismo, la importancia que tienen sus penes en su trabajo, al descubrir que la gran mayoría de travestis publica en estos portales fotos donde se los ve erectos y son plenamente exhibidos. Se contempla, pues, que en sus anuncios, en un espacio reducido, se pueden concentrar como en ningún otro sitio los aspectos que son más valorizados en el mercado del sexo local. De forma ambivalente, ellas deben resaltar cuán "bellas" y "femeninas" son y, al mismo tiempo, expresar la capacidad que tienen para hacer gozar, sobre todo mediante la penetración, a sus clientes.

Para finalizar, a diferencia de las mujeres trabajadoras del sexo, las travestis relacionan su brasileñidad tanto con sus formas corporales y "belleza" como con la manera de desenvolverse sexualmente; es decir, se consideran buenas amantes con una dotación muy "adecuada" para dar placer. Se aprecia que en el proceso de resaltar su "singularidad" como travestis brasileñas se apropian de un discurso dominante patriarcal que sexualiza la brasileñidad. Si bien este discurso tiene sus raíces en una ideología colonial donde las mujeres mulatas y negras fueron y son erotizadas $^{31}$, se observa que el mismo traspasa sus vínculos

\footnotetext{
${ }^{31}$ En menor medida, los hombres "negros" también son sexualizados. Según Moutinho (2004:360), las características estigmatizadoras de la "raza negra" acaban por revelarse como elementos de prestigio en el mercado erótico/afectivo, diseñando al hombre "negro" (más "viril", "bien dotado", "más caliente", con "mejor desempeño sexual"). También la autora (Moutinho, 2006) analiza el mercado sexual homoerótico en Río de Janeiro donde turistas "blancos" (europeos y norteamericanos) buscan mantener relaciones sexuales con hombres "negros" por considerarlos más "fogosos" y "calientes". Por su parte, Pinho
} 
"raciales" para convertirse en una cuestión étnica: la identidad nacional brasileña, más allá del "color" y del género, adquiere frecuentemente un matiz sexual en sus tránsitos transnacionales. Dicha asociación es aprovechada - y realzada- por travestis insertas en el competitivo mercado del sexo para diferenciarse del resto y erigirse como las más "bellas" y "calientes".

\section{El mercado del sexo español}

Para comprender de forma cabal cómo las travestis accionan su brasileñidad en el territorio español, habrá que entender también cómo se desenvuelve el mercado del sexo en estas latitudes y cuáles son las dificultades actuales con las que las trabajadoras del sexo se enfrentan.

Como se anticipó, un porcentaje elevado de mujeres y trans que ejercen el trabajo sexual en España son inmigrantes. Aproximadamente, y según datos de ONG's que colaboran con mujeres y trans trabajadoras del sexo en Barcelona, entre un $70 \%$ y $90 \%$ de las trabajadoras del sexo son de nacionalidad extranjera. Una de las primeras dificultades que estas trabajadoras encuentran al iniciar sus proyectos migratorios es la entrada a Europa. Con el pretexto de regular los «flujos migratorios», los Estados dificultan las migraciones legales y persiguen las ilegales, fortaleciendo cada vez más los controles fronterizos. Sin embargo, este endurecimiento de las políticas migratorias no impide la llegada de personas extracomunitarias, sino que transforma la modalidad de hacerlo. Cuantas más restricciones existan para ingresar al territorio europeo, más personas recurrirán al apoyo de distintos tipos de redes que posibilitarán la migración. Una vez en territorio español, y cuando se acaba la estancia permitida como turista (de

(apud Lopes, 2011) describe el proceso de construcción del cuerpo "negro" de hombres de la periferia de Salvador de Bahía. Estos cuerpos, que se tornan más visibles que los "blancos", son representados como poseedores de una hipersexualidad y constituyen la marca de la sensualidad de la ciudad. 
tres meses) ${ }^{32}$ o según el visado de entrada yno se tiene ninguna posibilidad de renovarla o adquirir un permiso de estancia o residencia, muchas personas se encuentran en una situación administrativa irregular. Según la Ley de Extranjería ${ }^{33}$ no "tener papeles" expone a las personas, principalmente, a la constante amenaza de expulsión y a la imposibilidad de circular libremente por el territorio español. El miedo a la expulsión se puede tornar real frente a los frecuentes controles de identidad, amparados por la ley, a los que son sometidas las personas de nacionalidad extranjera por parte de la policía.

Por otra parte, la visibilidad del trabajo sexual callejero es un tema de central interés para los poderes públicos. La visibilidad de las mujeres que ofrecen sus servicios y negocian con clientes en la vía pública es un tema que se ha vuelto polémico y preocupa pues, en definitiva, su exposición molesta. Concretamente en la ciudad de Barcelona, una de las formas creadas por la administración para gestionar este fenómeno y contener las presiones políticas, mediáticas y vecinales, consiste en desplegar una serie de operativos policiales para "limpiar" las zonas más "problemáticas" de la ciudad. Se organizan grandes redadas conjuntas entre la Guardia Urbana (Policía Municipal) y la Policía Nacional, por cuestiones de extranjería, o de los Mossos d'Esquadra (Policía Autonómica), por operaciones antidrogas o contra la trata de personas. No obstante, como Fernández Bessa sostiene, "si bien la actuación policial se justifica en la detención

\footnotetext{
32 Generalmente, la gran mayoría de travestis accede al territorio español como ("falsas") turistas. Este método, no obstante, no garantiza la entrada al país. Agentes policiales que trabajan en los aeropuertos identifican, con un amplio margen de discrecionalidad, a las personas que, posiblemente, son "falsas turistas". Luego de un interrogatorio, si no convencen sus respuestas sobre los motivos para visitar España, es rechazado su ingreso al país y son devueltas al lugar de procedencia. A causa de la importante presencia de mujeres y travestis brasileñas en la industria del sexo española, este tipo de actuaciones policiales en materia de extranjería se centra, sobre todo, en los vuelos provenientes de países como Brasil (López Riopedre, 2010).

${ }^{33}$ Ley Orgánica 4/2000, de 11 de enero, sobre derechos y libertades de los extranjeros en España y su integración social.
} 
de proxenetas que puedan explotar a las prostitutas, en la práctica, la mayoría de estos procesos acaban con la expulsión de las mujeres inmigrantes que ejercen el trabajo sexual" (2010:148). En nombre de la trata de personas y la explotación de las mujeres se enmascaran redadas y controles rutinarios sobre la situación administrativa de las personas inspeccionadas.

La entrada en vigor, en enero de 2006, de la controvertida Ordenança de Mesures per Fomentar i Garantir la Convivència a la Ciutat de Barcelona (llamada Ordenanza Cívica) ha hecho que se volviera más crítico el libre ejercicio del trabajo sexual callejero en Barcelona. Sus sucesivas reformas conducen a un explícito endurecimiento delos artículos vinculados con la prostitución callejera. Se busca sancionar, con altas multas, tanto al cliente como a la trabajadora. El objetivo es, evidentemente, prohibir la prostitución en el espacio público.

En definitiva, el panorama se vuelve cada vez más complicado para quienes desean trabajar en el mercado del sexo español. Particularmente en Barcelona, existe una normativa municipal que se ha convertido en el discurso del orden en las calles y pretende erradicar la prostitución de las calles de la ciudad. También se pueden observar las nefastas consecuencias en el trabajo cotidiano de mujeres y trans trabajadoras del sexo, al examinar cómo operan las grandes redadas policiales en torno a la prostitución y al considerar las vitales implicaciones de estar "sin papeles" en España. Las políticas públicas se endurecen para que quienes se dedican al trabajo sexual callejero -en tanto actividad "indeseable" para el crecimiento urbanístico, económico y turístico de la ciudad- terminen "desapareciendo" de las calles. Su visibilidad molesta. Estas regulaciones contribuyen a que cada vez menos personas tengan la opción de trabajar en las calles y se generen otras estrategias alternativas a este prohibicionismo ya declarado. 


\section{Travestis en Barcelona}

Teniendo en cuenta lo expuesto, se comprende que el número de travestis brasileñas que se dedican a la prostitución en las calles sea cada vez menor, o si aún siguen en las calles muchas tengan que complementar esta modalidad de trabajo con otras formas de ofrecer sus servicios sexuales.En mi trabajo de campo en Brasil, el trabajo sexual de las travestis se concentró casi exclusivamente en las calles de Río de Janeiro, a diferencia de España donde el trabajo sexual está más diversificado. Tanto en los espacios donde ejercen su actividad (calle, pisos privados e Internet) como en la forma que se promocionan (Internet $y$ prensa), las variantes son más amplias no sólo en España, sino en Europa en general. La gran mayoría de travestis, en tanto ciudadanas de nacionalidad extranjera "sin papeles" y trabajadoras del sexo, transita como las mujeres por una doble ilegalidad (Teixeira, 2008). No obstante, en el caso de las travestis, hay que incorporar su identidad genérica como un elemento "extra" de discriminación y estigma. Aunque en la actualidad, en Europa, el rechazo social hacia las travestis no adquiere las trágicas dimensiones que tiene en Brasil y ellas son conscientes que aquí se sienten más "respetadas" y "libres", aún en España las personas trans siguen siendo discriminadas. Al mismo tiempo, a las restricciones de trabajar en la calle se suman los efectos de la llamada "crisis económica" que también afecta, según aseguran, la disponibilidad del dinero de sus clientes. A pesar de este horizonte que compromete el día a día de muchas travestis "europeas", a continuación se analizará cómo emplean algunas prácticas para asegurarse un lugar en el cada vez más competitivo y duro mercado del sexo español.

La gran mayoría de travestis se ha ido adaptando a las restricciones impuestas al espacio público para trabajar en la calle, y escoge espacios cerrados como los pisos para desarrollar su actividad. Existen dos modalidades de pisos: los de agencia (gestionados por una tercera persona) y los autogestionados (cuando una o dos travestis comparten el alquiler de un piso para 
vivir y trabajar). En el caso de los pisos de agencia, de organización más jerárquica, los mismos son regentados por una encargada que les cobrará el $50 \%$ de sus ingresos por el alojamiento, la comida y la publicidad de sus servicios sexuales si son "internas", es decir, si viven y trabajan en el mismo sitio. Quienes, por el contrario, cumplen un horario más limitado ya preestablecido y no viven allí, el porcentaje de las ganancias a compartir será menor. Las trabajadoras sexuales hablan de "hacer plaza" cuando acceden a este tipo de pisos por un tiempo establecido de 21 días (siguiendo el mismo ritmo del ciclo menstrual marcado por el trabajo sexual de las mujeres). "Hacer plaza" por este período de tiempo, suele ser una práctica muy extendida en el mercado del sexo, tanto de mujeres como de travestis. Generalmente, todos los pisos se reservan un espacio para quienes "hacen plaza", así pueden ofrecer más opciones a su clientela al renovar al menos una parte de sus trabajadoras. Se observa así que la movilidad es una de las principales estrategias utilizadas por las travestis para desenvolverse en el mercado del sexo español y europeo. El objetivo principal consiste en evitar el efecto "cara quemada" y ser una "novedad" para los clientes. Sus constantes y cada vez más frecuentes traslados a Holanda, Alemania, Suiza, Austria y Dinamarca, entre los países actualmente más buscados, son muy usuales una vez que aprovechan este sistema de trabajo en pisos tan organizado.

Dada las intensas persecuciones policiales y la mayor vulnerabilidad de quienes están "sin papeles", los pisos también pueden ser espacios donde se encuentra tranquilidad y más seguridad que en las calles. Por lo tanto, trabajar en pisos se ha convertido en una de las principales opciones laborales de las travestis brasileñas en Barcelona. Asimismo, a diferencia de sus prácticas sexuales empleadas en Brasil, en los pisos se ofrecen servicios muy diversificados. Comparado con la modalidad de trabajo en las calles, esta amplitud en los servicios que ofrecen se debe a que cuentan con mayor tiempo y privacidad pero, también, es una estrategia laboral para captar al cada vez más exigente cliente español. Como Pelúcio expresa (2011:205), las 
travestis saben que los españoles quieren más que "una mujer con polla". El siguiente anuncio seleccionado en Internet da cuenta de la variedad de repertorios sexuales que se pueden ofrecer:

Completísima, activa, pasiva, viciosa y amante del morbo. Sexo sin límites ni tabúes, me encantan los principiantes y las fantasías eróticas, hago de todo tipo de fiesta. Me encanta hacer el oral hasta el final (garganta profunda), besos con lengua, beso negro ${ }^{34}$, masajes eróticos, penetraciones mutuas, lluvia dorada ${ }^{35}$, transformismo, dilatación anal, sado. Tengo todos los juguetes, ropa y accesorios que te puedas imaginar... si eres principiante tranquilo, soy especialista en chicos nuevos en este mundo, y si eres un viciosillo cómo el que más voy a ser muy exigente, no vas a superarme. ${ }^{36}$

Mediante este repertorio de prácticas, los cuerpos de las travestis brasileñas que se prostituyen en España, se vuelven más flexibles para ajustarse a las lógicas del mercado del sexo nacional $e$ intentar sobresalir en un universo altamente competitivo $y$ azotado por la crisis económica. En las páginas Webs españolas más importantes donde se anuncian travestis, sólo en Barcelona, se pueden presentar aproximadamente entre 80 y 100 travestis. Se entiende, pues, la necesidad de distinguirse en los anuncios por medio de una serie de indicadores leídos tanto en los textos como en las fotografías que acompañan dicha información. Es importante, pues, describir una amplia oferta de prácticas sexuales ofrecidas y de "vender" cuán profesionales y "ardientes" pueden ser. Como se describió, en el caso de las brasileñas, frecuentemente sexualizan su brasileñidad, es decir, emplean su identificación como brasileñas para añadir un "plus" de fogosidad.

\footnotetext{
34 Significa besar o lamer el ano.

35 También conocida como urofilia, consiste en orinar sobre el cuerpo de la otra persona.

${ }^{36}$ Disponible en: <http://www.erosguia.com/es/ficha.php/6412/>. Acceso $30 / 4 / 12$.
} 


\section{Conclusiones}

La experiencia de campo junto a travestis brasileñas demostró que sus trayectorias espaciales son fundamentales para entender a las travestilidades. Para transformarse en travesti se requiere, generalmente, haber abandonado previamente el lugar de origen para comenzar a viajar. Un viaje que las llevará a explorar nuevos territorios físicos/geográficos y corporales. Cuando las travestis migran no sólo transitan por distintos territorios físicos, sino que al mismo tiempo están construyendo su propia identidad. Ciudades como Río de Janeiro y Barcelona son consideradas como dos escalas, entre otras, por las que las travestis transitan tanto para conseguir bienes económicos y simbólicos a través del trabajo sexual como para modificar sus cuerpos. La persona travesti es construida en estos tránsitos.

En este artículo me centré en sus migraciones transnacionales europeas. Sinónimo de "glamour", respeto, libertad y sofisticación, Europa sigue representando para las nuevas generaciones un ascenso económico y social, pues en tanto "europeas" pueden distinguirse del resto de sus compañeras para sentirse valoradas en sus regresos -permanentes o transitorios- a Brasil. Asimismo, fue importante considerar la historia de las migraciones de las primeras travestis que llegaron a París en los años setenta, puesto que fue allí donde comenzaron a transformar y embellecer sus cuerpos, fue en París donde las identidades travestis empezaron a gestarse.

Fue particularmente fructífero examinar la manera en que promocionan sus servicios a través de los anuncios en Internet. En sus migraciones transnacionales, específicamente en España, ellas accionan su brasileñidad, es decir, resaltan ciertas características ("somos más calientes", "sensuales", "tenemos cuerpos espectaculares") que fueron construidas a partir de relaciones históricas y coloniales de poder y que, incluso en la actualidad, siguen sexualizando a las mujeres brasileñas. Sin embargo, las travestis se apropian de su "particularidad" como brasileñas para encontrar una posición destacada en el competitivo mercado 
transnacional del sexo. En suma, las identidades son relacionales e importa distinguir en qué contextos ellas están siendo travestis, pues los diferentes territorios delimitan el modo en que ellas actúan y construyen sus travestilidades. Describí que en Barcelona el mercado del sexo era más amplio que en Río, pues no sólo se desenvolvía en las cada vez más controladas calles de la ciudad, sino también a través de pisos privados o de agencias. Asimismo, examiné que en este contexto ellas empleaban una serie de prácticas -que no son comúnmente utilizadas en Brasil- para sobresalir e imponerse en un mercado del sexo que está cada vez más afectado por los ajustes económicos que sufre el país: me refiero al alto nivel de movilidad (a otras ciudades españolas $\mathrm{y} / \mathrm{o}$ europeas) y a la capacidad de ofrecer una vasta variedad de servicios sexuales. A pesar de todo, Europa sigue siendo atrayente $e^{37}$, aunque muchas travestis tengan que reconfigurar sus estrategias laborales.

Finalmente, a nivel teórico propuse el empleo de la categoría 'migración trans' para, precisamente, considerar la particularidad de las migraciones de travestis, transexuales o transgéneros. En el caso estudiado en mi investigación, las travestis brasileñas no sólo migran para ganar dinero y encontrar un escenario atractivo para insertarse en el mercado sexual; tampoco lo hacen únicamente para vivir sus identidades de género con mayor libertad y en un entorno donde se sientan respetadas. Como ya anticipé, las travestis cuando migran también están construyendo su propia identidad, pues mientras van transitando por diferentes territorios están, al mismo tiempo, modificando y feminizando sus cuerpos. La variable espacial no puede ser considerada como una referencia superficial, anecdótica o "decorativa" de las experiencias migratorias de las

${ }^{37}$ Esta afirmación, no obstante, debe ser matizada pues será necesario hacer nuevas inmersiones en el campo para observar si el número de travestis que desean "viajar" no está, efectivamente, disminuyendo. Si bien es muy difícil cuantificarlas, se requerirá nuevas investigaciones para evaluar los efectos concretos de la llamada "crisis económica" europea en las elecciones migratorias de las travestis brasileñas. 
travestis. Por el contrario, sus movilizaciones a través del espacio construyen sus identidades.

\section{Referencias bibliográficas}

Agustín, Laura. Trabajar en la industria del sexo, y otros tópicos migratorios. San Sebastián, Gakoa Editores, 2004.

. Sexo y marginalidad. Emigración, mercado de trabajo e industria del rescate. Madrid, Editorial Popular, 2009.

BenedeTtI, Marcos. Toda feita: o corpo e o gênero das travestis. Rio de Janeiro, Garamond, 2005.

BRUSSA, Licia. Migración, trabajo sexual y salud: la experiencia de TAMPEP. In: OSBORNE, Raquel (ed.). Trabajador@s del sexo. Barcelona, Bellaterra, 2004, pp.193-205.

CANTÚ, Lionel. De Ambiente. Queer Tourism and the Shifting Boundaries of Mexican Male Sexualities. GLQ: A Journal of Lesbian and Gay Studies, 8 (1-2), 2002, pp.139-166.

CoRRÊA, Mariza. Sobre ainvenção da mulata. Cadernos Pagu (6-7), Campinas-SP, Núcleo de Estudos de Gênero-Pagu/Unicamp, 1996, pp.35-50.

DOEZEMA, Jo. iA crecer! La infantilización de las mujeres en los debates sobre "tráfico de mujeres". In: OsBORNE, Raquel (ed.).Trabajador@s del sexo. Barcelona, Bellaterra, 2004, pp. 151-163.

DUQUE, Tiago. Montagens e Des-Montagens: vergonha e estigma na construção das travestilidades na adolescência. Dissertação de Mestrado, Programa de Pós-graduação em Sociologia, Centro de Ciências Humanas, Universidade Federal de São Carlos, 2009.

EDMONDS, Alexander. No universo da beleza: notas de campo sobre cirurgia plástica no Rio de Janeiro. In: GoldENBERG, Mirian (org.). $\mathrm{Nu}$ \& Vestido. Dez antropólogos revelam a cultura do corpo carioca. Rio de Janeiro, Record, 2002, pp.189-261.

ESPEJO, Beatriz. La prostitución desde una visión transexual. In: HOLGADO FERNÁNDEZ, Isabel (ed.). Prostituciones. Barcelona, Icaria, 2008, pp.123-138. 
FERNÁNDEZ BESSA, Cristina. Movilidad bajo sospecha. El conveniente vínculo entre inmigración y criminalidad en las políticas migratorias de la Unión Europea. Revista Interdisciplinar da Mobilidade Humana, ano XVIII, n 35, 2010, pp.137-154.

FIGARI, Carlos. Eróticas de la disidencia en América Latina: Brasil, siglos XVII al XX. Buenos Aires, Fundación Centro de Integración, Comunicación, Cultura y Sociedad - CICCUS y CLACSO, 2009.

FORTIER, Anne-Marie. Making Home: Queer Migrations and Motions of Attachment. In: AHMED, Sara; CASTAÑEDA, Claudia; ForTIER, AnneMarie e MIMI Sheller (eds.). Uprootings/Regroundings. Questions of Home and Migrations. Oxford e New York, Berg, 2003, pp.115-135.

GARAIZABAL, Cristina e BRIZ, Mamen (coord.). La prostitución a debate. Por los derechos de las prostitutas. Madrid, Talasa, 2007.

GarCíA, Antonio García e OÑATE MARTínEZ, Sara. De viajes y cuerpos: proyectos migratorios e itinerarios corporales de mujeres transexuales ecuatorianas en Murcia. In: GARCÍA, Antonio; GADEA, María Elena y PEDREÑO, Andrés (eds.). Tránsitos migratorios: Contextos transnacionales y proyectos familiares en las migraciones actuales. Murcia, Universidad de Murcia, 2010, pp.361-403.

GORMAN-MURRAY, Andrew. Rethinking queer migration through the body. Social \& Cultural Geography, 8(1), 2007, pp.105-121.

GOULART, Gilson. Imagens em trânsito: narrativas de uma travesti brasileira. In: PISCITELLI, Adriana; ASSIS, Glaucia de Oliveira e OLIVAR, José Miguel Nieto (orgs.). Gênero, sexo, amor e dinheiro: mobilidades transnacionais envolvendo o Brasil. Campinas-SP, Núcleo de Estudos de Gênero-Pagu/Unicamp, 2011, pp.263-320.

GREeN, James. Além do Carnaval: a homossexualidade masculina no Brasil do século XX. São Paulo, Ed. Unesp, 2000.

Holgado Fernández, Isabel (ed.). Prostituciones. Barcelona, Icaria, 2008.

HOOKS, bell. Selling Hot Pussy.Representations of Black Female Sexuality in the Cultural Marketplace. In: CONBOY, Katie; MEDINA, Nadia e STANBURY, Sarah (eds.). Writing on the Body. Female Embodiment and Feminist Theory. New York, Columbia University Press, 1997, pp.113-128. 
HowE, Cymene; ZARAYSKY, Susanna e LORENTZEN, Lois.Transgender Sex Workers and Sexual Transmigration between Guadalajara and San Francisco. Latin American Perspectives, issue 158, 35(1), 2008, pp.31-50.

JULIANO, Dolores. La prostitución: el espejo oscuro. Barcelona, Icaria, 2002.

KING, Dave. Gender Migration: A Sociological Analysis (or The Leaving of Liverpool). Sexualities, 6 (2), 2003, pp.173-194.

KuliCK, Don. Travesti. Sex, Gender and Culture among Brazilian Transgendered Prostitutes. Chicago, University of Chicago Press, 1998.

KULICK, Don and Charles KLEIN.Scandalous Acts: The politics of shame among Brazilian travesti prostitutes. In: HOBSON, Barbara (ed.). Recognition Struggles and Social Movements. Contested Identities, Agency and Power. Cambridge, Cambridge University Press, 2003, pp.215-238.

LOPES, Moisés. A construção social da 'branquidade' em homossexuais masculinos do Brasil e da Argentina. Sexualidad, Salud y Sociedad, 8, 2011, pp.113-130.

LÓPEZ RIOPEDRE, José. Inmigración colombiana y brasileña y prostitución femenina en la ciudad de Lugo: Historias de vida de mujeres que ejercen la prostitución en pisos de contacto.Tesis de doctorado, Departamento de Sociología I, Facultad de Ciencias Políticas y Sociología, UNED, 2010.

LUIBHÉID, Eithne. Queer/Migration.An Unruly Body of Scholarship.GLQ: A Journal of Lesbian and Gay Studies, 14 (2-3), 2008, pp.169-190.

MAYORGA, Claudia. Cruzando fronteiras. Prostituição e imigração. Cadernos Pagu (37), Campinas-SP, Núcleo de Estudos de GêneroPagu/Unicamp, 2011, pp.323-355.

MOUTINHO, Laura. Razão, "cor" e desejo: uma análise comparativa sobre relacionamentos afetivo-sexuais "inter-raciais" no Brasil e na África do Sul. São Paulo, Unesp, 2004.

. Negociando com a adversidade: Reflexões sobre "raça", (homos)sexualidade e desigualdade social no Rio de Janeiro. Revista Estudos Feministas, 14 (1), Florianópolis-SC, UFSC, 2006, pp.103-116. 
OliveIRA, Neuza Maria de. Damas de Paus: O jogo aberto dos travestis no espelho da mulher. Salvador, Centro Editorial e Didático da UFBA, 1994.

OSBORNE, Raquel. Las prostitutas: una voz propia (Crónica de un encuentro). Barcelona, Icaria, 1991.

PARKER, Richard. Abaixo do Equador. Culturas do desejo, homossexualidade masculina e comunidade gay no Brasil. Rio de Janeiro, Record, 2002.

PATRíCIO, Maria Cecília. No truque: transnacionalidade e distinção entre travestis brasileiras. Tese de doutorado, Programa de Pós-graduação em Antropologia da Universidade Federal de Pernambuco, 2008.

PELÚCIO, Larissa. Travestis brasileiras: singularidades nacionais, desejos transnacionais. 26a Reunião Brasileira de Antropologia, Porto Seguro, Bahia, 2008, pp.1-24.

. Abjeção e Desejo: uma etnografia travesti sobre o modelo preventivo de aids. São Paulo, Annablume/Fapesp, 2009a.

- "Sin papeles" pero con glamur. Migración de travestis brasileñas a España. (Reflexiones iniciales). Vibrant 6 (1), 2009b, pp.170-197.

. "Amores perros" - sexo, paixão e dinheiro na relação entre espanhóis e travestis brasileiras no mercado transnacional do sexo. In: PISCITELl, Adriana; ASSIS, Glaucia de Oliveira e OlIVAR, José Miguel Nieto (orgs.). Gênero, sexo, amor e dinheiro: mobilidades transnacionais envolvendo o Brasil. Campinas-SP, Unicamp/PAGU, 2011, pp.185-224.

PERES, Wiliam Siqueira. Subjetividade das Travestis Brasileiras: da vulnerabilidade da estigmatização à construção da cidadania. Tese de doutorado, Programa de Pós-graduação em Saúde Coletiva da Universidade Estadual do Rio de Janeiro, 2005.

PheTERSON, Gail (comp.). Nosotras, las putas. Madrid, Talasa, 1989. . El prisma de la prostitución. Madrid, Talasa, 2000.

PICHARDO, José Ignacio. Migraciones y opción sexual. In: Guasch, Óscar y Olga Viñuales (eds.), Sexualidades. Diversidad y control social. Barcelona, Bellaterra, 2003, pp.277-297. 
PIERROT. Memorias Trans. Transexuales-Travestis-Transformistas. Barcelona, Morales i Torres Editores, 2006.

PISCITElli, Adriana. Entre a praia de Iracema e a União Européia: turismo sexual internacional e migração feminina. In: PISCITELLI Adriana; GREGORI, Maria Filomena e CARRARA, Sérgio (orgs.). Sexualidades e saberes: convenções e fronteiras. Rio de Janeiro, Garamond, 2004, pp.283-318.

Corporalidade em confronto. Brasileiras na indústria do sexo na Espanha. Revista Brasileira de Ciências Sociais, 22(64), 2007, pp.17-32.

. Tránsitos: circulación de brasileñas en el ámbito de la transnacionalización de los mercados sexual y matrimonial. Horizontes Antropológicos, 15(31), 2009, pp.101-136.

¿Actuar la brasileñidad? Tránsitos a partir del mercado del sexo. Etnográfica, 15(1), Lisboa, 2011, pp.5-29.

PISCITELli, Adriana; AsSIS, Glaucia de Oliveira e OlIVAR, José Miguel Nieto (orgs.). Gênero, sexo, amor e dinheiro: mobilidades transnacionais envolvendo o Brasil. Campinas-SP, Núcleo de Estudos de Gênero-Pagu/Unicamp, 2011.

PONTES, Luciana. Mulheres brasileiras na mídia portuguesa. Cadernos Pagu (23), Campinas-SP, Núcleo de Estudos de GêneroPagu/Unicamp, 2004, pp.229-256.

SILVA, Hélio. Travesti: a invenção do feminino. Rio de Janeiro, Relume Dumará, 1993.

TeIXEIRA, Flávia do Bonsucesso. L'Italia dei Divieti: entre o sonho de ser européia e o babado da prostituição. Cadernos Pagu (31), CampinasSP, Núcleo de Estudos de Gênero-Pagu/Unicamp, 2008, pp.275-308.

. Juízo e Sorte: enredando maridos e clientes nas narrativas sobre o projeto migratório das travestis brasileiras para a Itália. In: PISCITELLI, Adriana; ASSIS, Glaucia de Oliveira e OlivAR, José Miguel Nieto (orgs.). Gênero, sexo, amor e dinheiro: mobilidades transnacionais envolvendo o Brasil. Campinas-SP, Núcleo de Estudos de Gênero-Pagu/Unicamp, pp.225-262.

TREVISAN, João. Devassos no paraíso: a homossexualidade no Brasil, da colônia à atualidade. Rio de Janeiro, Record, 2007 [1986]. 
312 Migraciones trans

VALE, Alexandre Fleming Câmara. O Vôo da Beleza: travestilidade e devir minoritário. Tese de Doutorado, Programa de Pós-graduação em Sociologia, Universidade Federal do Ceará, 2005.

- Migração, sexualidade e prostituição: travestis $e$ transgêneros no Bois de Boulogne. $33^{\circ}$ Encontro Anual da Associação Nacional de Pós-Graduação e Pesquisa em Ciências Sociais, Caxambu-MG, 2009, pp.1-28.

Vogel, Katrin. The Mother, the Daughter, and the Cow: Venezuelan Transformistas' Migration to Europe. Mobilities, 4(3), 2009, pp.367-387. 